\title{
Introduction March 2021 issue
}

\author{
Frank Cowell $^{1} \cdot$ Cecilia García-Peñalosa ${ }^{2}$
}

Received: 8 February 2021 / Accepted: 8 February 2021 / Published online: 23 February 2021

(C) The Author(s), under exclusive licence to Springer Science+Business Media, LLC part of Springer Nature 2021

The events of 2020 have shocked not only our personal lives but also our academic community. Economists throughout the world have pondered the implications and consequences of the global health shock brought about by COVID-19 and distributional issues have been at the forefront of both the academic and the policy debate. The Journal of Economic Inequality is an obvious outlet for this debate and later this year we will be publishing a special issue "Pandemics and Economic Inequality", a collection of papers on how pandemics have and will affect the distribution of income and wealth.

One of the questions in the minds of both policy-makers and academics interested in inequality has been to what extent COVID-19 will imply a setback to the United Nations' 2030 Agenda for Sustainable Development. Adopted in 2015 by heads of State and Government with a commitment to eradicate poverty and achieve sustainable development by 2030 world-wide, the Agenda consisted of 17 Sustainable Development Goals (SDGs) and 169 targets, in which ending poverty and fighting inequality play a major role. Differential access to healthcare, the sectoral nature of lockdowns, and even the unequal sharing of burdens within households made it clear from the start that the current pandemic would have major distributional consequences that risked delaying the attainment of these goals.

Many of the SDG targets are closely related to the topics that are at the heart of this Journal, and research published by our colleagues in this field over several decades has helped define and will help assess these targets. Consequently, in the early summer 2020, the Journal and Springer decided to produce a virtual special collection issue on "Sustainable Development Goals and the Study of Economic Inequality" that brought to light previously published articles related to the UN SDGs. Our aim with the issue was to reflect on economic perspectives and methods that are related to different dimensions of inequality highlighted in the SDGs. Moreover, given the limited range of activities available for many of us during the summer of 2020, an additional objective was to facilitate access to these debates for all those with time in their hands and a need to think about our changing world. The selected articles were hence made available to non-subscribers throughout the summer.

Frank Cowell

f.cowell@1se.ac.uk; f.cowell@gmail.com

1 London School of Economics and Political Science, London, England

2 Aix-Marseille University, CNRS, EHESS, and AMSE, Marseille, France 
Ravi Kanbur kindly agreed to select the articles of the special collection issue and write an introduction. The interest that his introduction has raised amongst readers has led us to now publish it in this issue. As it argues, the papers selected highlight to what extent the policy discourse that underlies the SDGs relies on the research made by those working on economic inequality. For over a century economists have been thinking about how to measure, explain, predict and affect economic inequality. In the past two decades many of these questions have been slowly moving to the front of the political debate and the inequality concerns present in the SDGs are an example. The COVID-19 pandemic will reinforce this.

The article gives a bird's-eye perspective on the study of economic inequality and the evolution of the field and highlights the extent to which the SDGs are concerned with distributional issues, even in the case of goals other than that specifically concerned with inequality (SDG-10). Ravi's article teaches us two important lessons. The first is that this is a field in which measurement is particularly important. As many of us know, the first reply we need to give to the student, journalist or policy maker asking us a question on inequality is "inequality of what amongst whom?"; the second is a caveat about the complexity of providing a measure for inequality. Ravi's second lesson is to emphasize the importance of fundamental research in social sciences. Of course the policy discourse may guide the focus of some of our research, but fundamental research, asking questions just for the sake of curiosity, can turn out to have a major influence on the policy discourse too. Going back to past issues hence seems particularly important at this moment in which the pandemic seems to have given a feeling of urgency to all we do.

Publisher's Note Springer Nature remains neutral with regard to jurisdictional claims in published maps and institutional affiliations. 